BULLETIN Bulletin hispanique

HispaniQuE Université Michel de Montaigne Bordeaux

120-1 | 2018

Varia

\title{
Declaración magistral destos versos de Juvenal, sátira 6 (1632) de Bartolomé Jiménez Patón
}

fuentes y contenido

Commentaire magistral de ces vers de Juvénal, satire 6 (1632) de Bartolomé

Jiménez Patón : sources et contenu

'Masterful Commentary of those verse by Juvenal, satire 6' (1632), by

Bartolomé Jiménez Patón: sources and content

\section{Catalina Monserrat Roig}

\section{OpenEdition}

\section{Journals}

Edición electrónica

URL: https://journals.openedition.org/bulletinhispanique/5671

DOI: 10.4000/bulletinhispanique.5671

ISSN: 1775-3821

Editor

Presses universitaires de Bordeaux

Edición impresa

Fecha de publicación: 30 junio 2018

Paginación: 185-206

ISBN: 979-10-300-0298-0

ISSN: 0007-4640

Referencia electrónica

Catalina Monserrat Roig, «Declaración magistral destos versos de Juvenal, sátira 6 (1632) de Bartolomé Jiménez Patón», Bulletin hispanique [En línea], 120-1 | 2018, Publicado el 01 enero 2022, consultado el 07 enero 2022. URL: http://journals.openedition.org/bulletinhispanique/5671 ; DOI: https://doi.org/ 10.4000/bulletinhispanique.5671 


\title{
Declaración magistral destos versos de Juvenal, sátira 6 (1632) de Bartolomé Jiménez Patón: fuentes y contenido ${ }^{1}$
}

\author{
Catalina Monserrat Roig \\ Instituto de Estudios Hispánicos en la Modernidad- \\ Universitat de les Illes Balears
}

En 1632 Jiménez Patón publie la Déclaration magistrale où il commente quelques vers de la Satire VI de Juvénal. Dans cet article sont étudiées les sources du texte de Patón : auteurs latins et grecs, textes bibliques et chrétiens et commentateurs des auteurs classiques. Est également analysé le contenu du commentaire qui, partant d'une critique de l'ambition des femmes, se centre sur le sabbat et d'autres traits distinctifs des Juifs.

Mots-clés : Humanisme, Littérature gréco-latine, Bartolomé Jiménez Patón.

En 1632 Jiménez Patón publica la Declaración magistral que comenta unos versos de la sátira 6 de Juvenal. En el presente trabajo se estudian las fuentes del texto patoniano: autores latinos y griegos, textos bíblicos, cristianos y comentaristas de autores clásicos. Asimismo se analiza un contenido que, partiendo de la crítica a la ambición femenina, se centra en el sabbat y otros rasgos de los judíos.

Palabras clave: Humanismo, Literatura grecolatina, Bartolomé Jiménez Patón.

In 1632 Jiménez Patón publishes a «Declaración magistral» commenting on a small number of verses in Juvenal's satire VI. This work studies the sources of the Patonian text: Latin and Greek authors, Biblical and Christian texts, and commentators of classical authors. It also analyses the content of the commentary which, from the criticism of women's ambition, is centered on Sabbath and other Jewish features.

Keywords: Humanism, Greco-Latin Literature, Bartolomé Jiménez Patón.

1. Este estudio se ha escrito en el marco del proyecto «Edición crítica y estudio de los Comentarios de erudición (1621), y de otros textos inéditos, del Maestro Bartolomé Jiménez Patón (1569-1640) II» (FFI2011-22906), financiado por la Dirección General de Investigación y Gestión del Plan Nacional de I+D+i del Ministerio de Ciencia e Innovación. 
En su obra más destacada, La elocuencia española en arte (1604, 1621), y también en otras como Apología de la Lengua Española², Bartolomé Jiménez Patón defendió la importancia de la enseñanza y la publicación en lengua castellana. De este posicionamiento, como bien demuestran Maria del Carme Bosch y Jaume Garau en diversos estudios (Bosch 2001-2002, 2009, 2012, Garau 2014b, Garau y Bosch «Estudio preliminar» a Jiménez Patón 2014), no debe implicarse que el maestro de Villanueva de los Infantes no otorgara a la lengua latina y al mundo clásico, en el sentido más amplio, un lugar central para la formación y el saber del hombre de su tiempo (Garau 2014b: 100-101, Garau 2012: 240)3.

Dejando de lado las constantes referencias a los autores latinos y griegos presentes en sus obras, que le permiten mostrar una erudición deslumbrante tan propia de los humanistas de la época y presentarlos como argumentos de autoridad, Patón también produjo algunas obras dedicadas precisamente a la traducción y explicación de autores clásicos. Es el caso del comentario del «Libro III» de las Odas de Horacio que aparece en el «Libro decimosexto» del manuscrito recuperado de los Comentarios de erudición, estudiado y editado críticamente por María del Carmen Bosch, Jaume Garau, Abraham Madroñal y Juan Miguel Monterrubio, en el año 2010, y el manuscrito inédito titulado Cátedra de erudición, donde traduce a Marcial. También lo son, y este es precisamente el objeto de la investigación que actualmente nos ocupa, las Declaraciones magistrales de Marcial y la Declaración magistral destos versos de Juvenal, sátira 6 (1632).

Estas fueron tratadas en su día por Theodore Beardsley (Beardsley 1978 y 1986). En el primer trabajo el estudioso americano se ocupa de las Declaraciones de Marcial, establece su número en dieciocho y examina la cuestión de su publicación, un aspecto para nada baladí, porque, como afirma el propio autor y lo ilustra su trabajo, «los meros detalles de publicación de las Declaraciones presentan un verdadero rompecabezas, y casi parece que se trata de una conspiración festiva para fastidiar al bibliógrafo futuro» (Beardsley 1978: 92). En el segundo trabajo, no centrado únicamente en las declaraciones, Beardsley tampoco entra en cuestiones de contenido sino que defiende la tesis de que fueron publicadas como piezas separadas. Afirma además que Patón tenía la intención de que las Declaraciones de Marcial-los 19 sueltos de

2. Discurso impreso al final del Perfecto predicador. Ver en la edición de Madroñal (2009: 269-274).

3. Como explica Garau, por su faceta de maestro estimó su conocimiento como un instrumento indispensable para los estudios gramaticales; por la de humanista lo vio útil para cualquiera que pretendiera dedicarse a disciplinas como podían ser la medicina o el derecho; y, por último, pero no por ello menos importante, por su condición de notario del Santo Oficio, sostuvo que la lengua latina permitía leer la Vulgata y también hallar la ortodoxia, tan necesaria en su parecer, en la Espańa de la Contrarreforma. 
Marcial (1627-1628) (Beardsley 1986: 11) ${ }^{4}$-, la Declaración magistral destos versos de Juvenal, sátira 6 (1632) y la Declaración preámbula del salmo 118 (1633) integraran un volumen adicional que completaría los ocho volúmenes de sus Comentarios de erudición (Beardsley 1986: 11). Fueron crematísticas las razones que llevaron al maestro a la publicación por separado de todas estas declaraciones: precisamente para obtener los fondos que le permitieran la publicación de su magna opera, los Comentarios de erudición.

Juan Gil en su trabajo "Marcial en Espańa» dedica tres páginas a las declaraciones patonianas sobre Marcial (Gil 2004: 309-311). Gil da noticia únicamente de ocho de ellas, ofrece el título, la equivalencia con las ediciones modernas del número de epigrama en el caso que no coincida con el del título y la cuestión sobre la que versan (Gil 2004: 310)5. Abraham Madroñal (2009: 174-175) también ofrece el registro de las Declaraciones magistrales de Marcial y añade cuatro más que, según sus investigaciones, se habrían perdido. Igualmente, Cózar Castañar indica las ocho Declaraciones magistrales de Marcial y la Declaración magistral de Juvenal contenidas en el volumen Colección de temas gramaticales de la Biblioteca Nacional de Espańa (Cózar Castañar 2007: 10-11).

Sea como sea, ni Beardsley, ni Gil, ni Madroñal analizan o editan críticamente las declaraciones y, de hecho, ni tan siquiera coinciden en las referencias de los epigramas y libros de Marcial. Esto justifica la necesidad de un estudio de todas ellas y de su edición crítica. Es el trabajo que con Jaume Garau venimos realizando desde hace un tiempo y que tiene como objetivo la publicación de dicho estudio y edición crítica.

No obstante, nos centraremos aquí únicamente en la declaración de la sátira 6 de Juvenal. En realidad esta declaración supone un comentario de un reducido número de versos de la sátira latina pero aparece colmada de referencias, traducciones y comentarios de otros autores latinos, griegos y cristianos, de referencias bíblicas y hasta de comentaristas de autores clásicos. Entre estos últimos, está Juan Villén de Biedma y su obra Q. Horacio Flacco poeta lyrico latino. Sus obras con la declaracion Magistral en lengua Castellana, (Granada, 1599) ${ }^{6}$, que tiene el mérito de ser la primera traducción al castellano de la obra completa de Horacio, y de la que Menéndez Pelayo afirmó que estaba

4. Beardsley usa la expresión «19 sueltos» que, según deducimos páginas después (1986: 13), debe resultar al incluir la traducción con comentario del epigrama 92, libro 11 -aunque aquí se cite errónamente como epigrama 12, libro 11, el autor sí da la referencia correcta en Beardsley (1978: 92)-, que aparece en la Elocuencia española, reimpreso en su Mercurio Trimegisto fol. 124 $\mathrm{r}-\mathrm{v}$. Ahora bien, si los 19 sueltos son datados por Beardsley entre 1627-1628, no nos encaja que se trate de un texto ya publicado en otro anterior, como es la Elocuencia española de 1604, y su posterior inclusión en el Mercurio Trimegisto de 1621.

5. Sirva a modo de ejemplo : "5) Declaración magistral del dístico Epigrama de Marcial lib. 1. ep. 6 [= I 5], a Don Juan Chacón Narváez y Salinas. Sobre las fiestas celebradas por Domiciano en el anfiteatro y el castigo dado a las malas poesías.»

6. En ella el autor presenta el texto latino, la traducción en castellano y un comentario donde va intercalando las palabras latinas traducidas. 
hecha «rastrera y literalmente como para principiantes» (Menéndez Pelayo 1953: 87-88). Si la traemos a colación en este punto es para mostrar cómo las declaraciones magistrales son un género propio de la época y para destacar que el sentido de la expresión se correspondería con el más usual en nuestros tiempos de "comentario'. De hecho, en la declaración que nos ocupa, Patón afirma a propósito de unos versos de Juvenal "por esto dijo en los versos que se van declarando, [...]» (f. 3). El sentido de 'exponer', 'comentar' o 'interpretar' es evidente en sus palabras 8 .

En este contexto, y como ya hemos apuntado, en 1632 Patón publica la Declaración magistral destos versos de Juvenal, sátira 6, impresa en Cuenca por Salvador de Viader (Jiménez Patón 1632). Está encabezada por un breve prólogo dedicatorio escrito por el propio hijo del maestro, Alonso Patón y Monsalve (Madroñal 1993: 83-84, Bosch 2012: 180, Garau y Bosch «Estudio preliminar» a Jiménez Patón 2014: 18)9 .

La declaración empieza con cinco versos de la sátira 6 de Juvenal, los versos 156-160, cuya referencia concreta, como es usual en toda la declaración, no se nos ofrece. Los versos son los que siguen:

\author{
[...] adamas notissimus et Beronices \\ in digito factus pr<a>etiosior ${ }^{10}$; hunc dedit olim \\ barbarus incestae, dedit hunc Agrippa sorori, \\ obseruant ubi festa mero pede sabbat $<h>a^{11}$ reges \\ et uetus indulget senibus clementia porcis. ${ }^{12}$ Ivv. 6, 156-160
}

7. Ya en 1609 había aparecido en Burgos la declaración magistral de Persio realizada por Diego López con el título de Aulo Persio Flacco, traduzido en lengua castellana por Diego Lopez, natural de la Villa de Valencia, orden de Alcantara y preceptor en la ciudad de Toro, con Declaracion Magistral, en que se declaran todas las historias, fabulas, antiguedades versos difficultosos, y moralidad que tiene el poeta. El mismo autor años más tarde, en 1642, también publicó la Declaración Magistral sobre las Sátiras de Juvenal y Persio, Principes de los Poetas Satiricos que contiene los comentarios a los dos poetas.

8. Sentido confirmado por el Diccionario de Autoridades: Declarar: «Vale también exponer, comentar, interpretar lo que está obscuro o dificultoso de comprender».

9. En la impresión se lee "Monsalva" aunque debe tratarse de un error de imprenta. En este sentido afirma Madrońal: «Los datos que completan la biografía delineada por Maestre son los siguientes: que estudió en Madrid con los jesuítas, y en Baeza y Salamanca, donde alcanzó el grado de maestro; que se casó probablemente con una paisana de Almedina, llamada Juana Hervás Monsalve, de la cual tuvo dos hijos». Garau y Bosch en el «Estudio preliminar» a $E l$ virtuoso discreto. Primera y segunda parte de Jiménez Patón transcriben la dedicatoria de Jiménez Patón a sus hijos «Felis y Alonso Patón y Monsalve» en el prólogo (f. 5) de la primera parte de El virtuoso discreto.

10. Se han elidido con corchetes angulares los elementos sobrantes que figuran en la impresión del texto.

11. En el impreso de la declaración magistral aparecen de manera sistemática las formas sabbatha, sabbathum, sabbatho tanto en el texto de Patón como en el que cita de autores, comentaristas o textos bíblicos. Las formas de los textos originales no contienen en ningún caso la grafía $h$ y, por tanto, en nuestro trabajo oferecemos las palabras corregidas.

12. En el presente estudio citamos los autores latinos siguiendo el índice del Thesaurus Linguae Latinae (Lipsiae, in aedibus B. G. Teubneri, 1904) y los textos de dicha editorial. Los autores giegos son citados por el A Greek-English Lexicon (Oxford, Clarendon Press, 1996). Para los 
Consideramos oportuno señalar que de la declaración magistral de Patón no debe esperarse un comentario de toda la sátira 6 de Juvenal puesto que únicamente trata doce versos de los 661 que integran la sátira. No en vano, el título ya lo indica: Declaración magistral destos versos de Juvenal, sátira 6 .

A propósito de la sátira 6 de Juvenal, conviene recordar que esta presenta el monotema de la crítica a la mujer casada, siguiendo la tradición griega de Semónides, Aristófanes o Teofrasto y, evidentemente, la tradición latina de Lucilio. El poeta de Aquino expone todos cuantos vicios, excesos y comportamientos depravados se puedan atribuir a una amplia galería de mujeres de la sociedad romana de su época. El motivo de tal embate es, según parece al comienzo, recriminar a un interlocutor ficticio, Póstumo, su intención de casarse. Presentando este elenco de defectos en las mujeres y, en consecuencia, de problemas para el marido, el poeta pretende convencer a su amigo para que no se despose (Beltrán y Sánchez-Lafuente 2008: 240-242) ${ }^{13}$. La detracción y el vituperio que reciben las mujeres han supuesto que esta sátira sea considerada una de las composiciones más misóginas cuando menos de la literatura latina. Veamos cómo comenta Patón sus versos.

\section{Períoca de la Declaración magistral destos versos de JuVEnal, sátira 6}

A partir de los versos 156-160 de la sátira 6 anteriormente reproducidos, Patón plantea la ambición del género femenino y su ansia por la ostentación de joyas y riquezas; afirma que las mujeres las desean, envidian las que posee su vecina $y$, aunque pongan en jaque las haciendas del marido, consideran que lo que no se tiene en casa, pero el vecino posee, se debe comprar ${ }^{14}$. Además, las mujeres quieren conseguir las joyas más valiosas, como los diamantes y, más todavía, el diamante que recibió Berenice de su hermano Agripa. De estos dos personajes Patón presenta algunos datos genealógicos y la noticia de una supuesta relación incestuosa.

Los versos 357-364 de la sátira 6 sirven al maestro para ahondar en la idea de que las mujeres, llevadas por tal ambición, piden al marido cuanto desean,

textos cristianos usamos la Patrologia Latina de Migne, http://www.documentacatholicaomnia. eu. Ya a propósito de los versos citados, hemos respetado la forma "Beronices» utilizada por Patón (lectura E. Mico de la edición Teubneriana). Nosotros, en cambio, hemos utilizado la generalizada «Berenice» y, en lo que atańe a los autores latinos, reproducimos la forma que las ediciones modernas ofrecen.

13. Como es sabido, este tópico es heredado en la literatura española por Francisco de Quevedo, contemporáneo y amigo de Patón. Beltrán y Sánchez-Lafuente señalan la huella de Juvenal en la obra de Quevedo y, en concreto, en el Soneto 517 (Blecua 517, Parnaso 418 a) donde se refieren los defectos de la mujer casada y en el Soneto 639 (Blecua 639 y Parnaso 653) en el que aparecen los males del matrimonio.

14. Ivv. 6, 152. 
sin medida, sin considerar sus posibilidades y sin prestar atención alguna a las dificultades que le plantean.

Partiendo de la condición de judíos de Agripa y Berenice, Patón pasa a tratar el sabbat (fol. 2v). De este afirma que es el séptimo día de la semana y que es para los judíos, siguiendo el mandamiento de Dios, un día de fiesta que, en cambio, para los cristianos se trasladó al domingo. A continuación el maestro caracteriza el sabbat y aduce las menciones que de él y de la figura de Moisés hacen los autores griegos y latinos. Sigue con una digresión donde considera de nuevo la figura de Berenice y retorna a renglón seguido al tema del sabbat con la exégesis de la expresión «dies Herodis» del verso 180 de la sátira 5 de Persio. Patón parte de los versos de Juvenal 96-109 de la sátira 14 (citada, no obstante, como 15) y trata algunos rasgos que se atribuyen a la religión y al pueblo judío como, por ejemplo, el no comer carne de cerdo, o la circuncisión. Patón también comenta la crítica que el poeta latino hace de los romanos convertidos al judaísmo y destaca la dificultad que para los más jóvenes supone comportarse de modo avaricioso, «vicio antiguo en esta nación y hoy no dejado» (fol. 4). Sea como sea, el maestro aduce que los autores destacan como rasgo más distintivo de los judíos «la observancia de la fiesta del sábado» (fol. 4). Todos ellos llaman al sábado «séptimo día», si bien Horacio en la sátira 9 del libro 1, verso 69, usa «tricesima Sabbata», expresión problemática en cuanto a su significado y que el comentarista intenta esclarecer.

Con dos versos de Terencio el maestro finaliza la declaración retomando brevemente el tema de partida, el despilfarro en las mujeres que, llevadas por su ambición en galas, empobrece a los maridos.

\section{ANÁlisis de LA DEClaración MAGISTRAL ATENDIENDO}

\section{A SU CONTENIDO Y A SUS FUENTES}

Veamos con más detalle la exposición de los contenidos, considerando a la vez las fuentes clásicas, bíblicas y cristianas que usa Patón, pues separar los dos aspectos dificultaría el trabajo y nos supondría repeticiones innecesarias.

\subsection{La ambición de galas y joyas en las mujeres y su deseo de ostentación}

La primera cuestión que aborda Patón en su comentario es la ambición de galas y joyas en las mujeres y su deseo de ostentación de riquezas. Este asunto inicia y concluye la declaración magistral y el maestro no escatima la crudeza en su ataque contra tales defectos, remarcando especialmente los problemas que las mujeres ocasionan al marido. Veamos dos ejemplos de ello:

Una es la que toca en estos versos, dependientes de los de arriba, en que refiere la ambición de galas y joyas en las mujeres y el querer parecer y ser tenidas por muy ricas, pues que si toman la mano a mandar en casa ¡Dios nos libre! Y si la vecina tiene 
algunas prendas y estimación y ella no, aunque se empeñe y venda, el pobre marido se ha de traer el vestido nuevo, el pendiente curioso, la gala al uso. (fol. 1v)

\section{Igualmente:}

Juvenal, pues, para significar la ambición destas galas y joyas en las mujeres, dice que, aunque sea la joya de una reina, luego quieren otra como ella. Y aun porque sea la misma, si les es posible, harán todas sus diligencias que, aunque no haya qué comer, quieren andar galanas como las más poderosas y ricas ${ }^{15}$. Porque (como adelante en esta misma sátira dice) muchas dellas, aunque son pobres, no reparan en ello, ni tienen vergüenza, ni se miden con el caudal de su casa. Antes piden con gran desvergüenza, como si manara su casa oro y plata, y como si la hacienda del marido fuera de un enemigo. [...] Y manifiesta estas insaciables ansias con decir que piden cualesquier joyas que ven, aunque sean tan preciosas como el diamante desta judía. (fol. 2) (6 $^{16}$

La reina y judía que Patón menciona es Berenice, un personaje femenino que ya en la Antigüedad no quedó libre de controversia por su comportamiento con los hombres y que supuso, por tanto, un excelente ejemplo de mujer criticable. En este caso, se destaca una supuesta relación incestuosa con su hermano Agripa, y se da noticia de algunos hechos biográficos que sirven a Patón para abonar la crítica a las mujeres. Este pasaje nos permite entrar también en el uso patoniano de las fuentes grecolatinas, bíblicas y cristianas. Reproducimos el texto:

Uno dellos [un diamante] le presentó Agripa a su hermana Beronices, estando amancebado con ella, que por eso dice incestae sorori. Y fue así que Agripa, el cual fue rey de los judíos después de muerto Tiberio ${ }^{17}$, en su muerte dejó un hijo de su mismo nombre, de edad de diez y siete ańos, y tres hijas, Drusila, María y

15. El pasaje anterior y, hasta este punto, el presente suponen una interpretación de Patón de los versos de Ivv. 6, 149-157. El resto de la cita corresponde a su comentario a Ivv. 6, 357-364. En todo caso, el maestro ha omitido la citación y explicación de los versos 359-361; en ellos Juvenal contrapone los hombres a las mujeres y destaca que estos, al menos alguna vez, son más cautelosos en su dispendio, pues temen la pobreza a la que un gasto desmedido los puede llevar.

16. El texto que va desde "antes piden con gran desvergüenza» hasta el final de la cita se debe únicamente a la interpretación de Patón, pues no se deduce del texto de Juvenal que sean artículos de lujo que la mujer pida al marido. De hecho, en los versos anteriores al verso 156 el poeta latino cita otros objetos de gran valor que son adquiridos por las mujeres y que no son reproducidos por Patón. La referencia del maestro al diamante recupera aquí los versos 156 y 157 que inician la declaración magistral.

17. Herodes Agripa I era hijo de Aristóbulo IV y nieto de Herodes el Grande. Se educó en Roma con Druso, el hijo del emperador Tiberio, así como con su sobrino, Claudio. Calígula, después de la muerte de Tiberio, lo nombró rey de Batanea (37 d.C); Agripa I vio incrementados sus dominios con territorios de Galilea y de Perea (39 d.C.); finalmente Claudio le concedió los territorios de Judea y Samaria, así como el reino de Lisanias, convirtiéndose de este modo en rey de toda Judea (41 d.C.). Herodes Agripa hizo ejecutar al apóstol Jacobo (más conocido como Santiago el Mayor) -Vvlg. act. 12, 1-2. Su muerte se sitúa en el 44 d.C., según las fuentes bíblicas ejecutado por el ángel de Dios -Vvlg. act. 12, 20-23. 
Beronices ${ }^{18}$, de diez y seis años, esta casada con su tío Herodes, rey de Calcis ${ }^{19}$. Murió Herodes, su tío y marido, y amancebose con su hermano Agripa ${ }^{20}$. Y tal fama tuvo como lo dice aquí el poeta, y en estos amores le presentó este preciosísimo diamante. Pretendiola en casamiento Polemón, rey de Licia, tan enamorado della que, siendo gentil, se circuncidó por alcanzarla por mujer, con que se puso silencio al mal nombre de amancebada con su hermano, como lo cuenta Josefo en el libro último de sus Antigüedades. (fol. 2)

Patón proporciona aquí la referencia clásica: Flavio Josefo en el último libro, por tanto, el libro 20, de las Antigüedades Judaicas ${ }^{21}$. La obra de Flavio Josefo, como es sabido, está escrita en griego y, como ya demostró M. del Carme Bosch en diversos trabajos («Estudio preliminar» a Jiménez Patón 2010: 4243, n. 79, y a Jiménez Patón 2014: 60), Patón no sabía griego y, por tanto, no podía acceder al autor de manera directa. Es más, en el pasaje anterior el maestro comete un error, habla de "Polemón, rey de Licia», el hombre que se circuncidó, es decir, se convirtió al judaísmo, para casarse con Berenice. Pues bien, según las fuentes históricas, Berenice se casó con Polemón II, rey de Cilicia. Patón confunde, por tanto, el reino de Cilicia con el de Licia. ¿Es este un error atribuible únicamente a nuestro autor? Sin duda, la respuesta es que no. Nos explicamos. El estudio que hemos realizado de la declaración nos ha revelado que en muchos puntos Patón sigue uno de los comentaristas más prestigiosos de Juvenal, el humanista Juan Británico. En su comentario a la sátira 6 podemos leer (s.v. in digito Berenices) "Polemoni regi Lyciae» (Britannicus 1551: 107) ${ }^{22}$. Mientras que aparece como «rey de Cilicia» en las

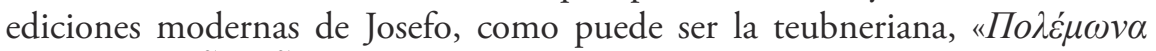

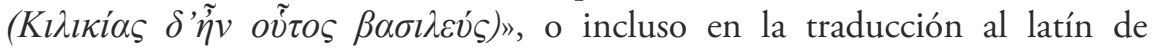
Segismundo Gelenio de 1554, Polemoni regi Ciliciae (Gelenius (1554: 540) y

18. Las fuentes clásicas presentan a Berenice, además de como nos la mostrará Patón, como amante del emperador Tito. Suetonio afirma que el emperador le llegó a pedir matrimonio: «nec minus libido propter exoletorum et spadonum greges propterque insignem reginae Berenices amorem, cum etiam nuptias pollicitus ferebatum -Svet. Tit. 7. Incluso fue designada como esposa del emperador, Ps. Avr. Vict. epit. 10, 4.

19. Se trata de Herodes Polio, hermano de Herodes Agripa I. Fue rey de Calcis (41-48 d.C.), capital en diversas épocas de la región de Iturea, al noreste de Palestina y en la ladera occidental de la cordillera del Antilíbano.

20. Patón se refiere aquí a Herodes Agripa II, rey de Judea (28 d.C.-ca.100 d.C). Era hijo de Herodes Agripa I y su esposa Cipros. Al morir Herodes Agripa I, los territorios que le pertenecían fueron dirigidos por gobernadores hasta que pasaron a manos de Agripa II quien se convirtió así en el ańo 48 d.C. en rey de Calcis -antes dominio de su tío, Herodes Polio- y en el 52 d.C en rey de Judea. Después de la destrucción de Jerusalén (70 d.C.), se trasladó a Roma con su hermana Berenice donde recibió el cargo de pretor y murió sin descendencia alrededor del año 100 d.C.

21. En las ediciones modernas la cita corresponde a J. AJ 20, 7, 3.

22. La edición consultada es Britannicus, Iunii Iuvenalis et A. Persii Flacci Satyrae, Basileae, 1551. Se trata de una edición que contiene los comentarios de Británico a Juvenal y, en relación a Persio, presenta los comentarios de Badio Ascensio y Británico y las explicaciones de Plautio y Antonio de Nebrija. En el presente trabajo lo citamos como Britannicus (1551), pues únicamente nos referimos a la parte atribuida a Juan Británico y no a los otros humanistas. «Haec post mortem Herodis [...], suasit Polemoni regi Lyciae, ut circumfusus eam haberet uxorem.» 
también en la versión greco-latina del mismo autor en la edición consultada

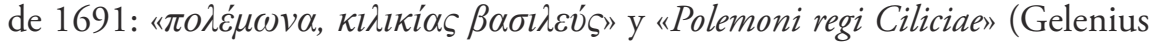
1691: 693) ${ }^{23}$.

Este error y otros aspectos que iremos exponiendo nos hacen pensar que el comentario de Británico fue seguido por Patón para elaborar la declaración que nos ocupa.

Si en la sátira 6 de Juvenal la crítica a los defectos de las mujeres es el armazón que sustenta el poema, aquí, no obstante, el tema de la mujer se ha convertido en un mero pretexto. Lo que centra la atención de Patón, como veremos a continuación, es la cuestión del sabbat y de otros aspectos relacionados con los judíos.

\subsection{El sabbat}

Sin duda el sabbat es el tema central del texto que estudiamos. En el folio 1v Patón, partiendo de los versos 156-158 de la sátira 6, al introducir las figuras de Agripa y Berenice y para dar cuenta de su origen judío, parafrasea los versos 158-160 de la sátira 6 de Juvenal ${ }^{24}$ :

Esta dona ${ }^{25}$ y joya dio a la incestuosa hermana en aquella tierra, donde los reyes celebran la fiesta de los sábados con pies descalzos y por antigua observancia no comen puercos y les dejan morir de viejos, que es decir en Judea. (fol. 1v)

Y retoma poco después el verso 159: "Y para decir que Agripa y Beronice, su hermana, eran judíos, dice: "Obseruant ubi festa mero pede Sabbata reges" " (fol. 2-2v) que da pie a Patón para tratar el sabbat. De este afirma que es el séptimo día de la semana, día en que, "no crió Dios más que al mismo día, como consta del Génesis capítulo 2, "Requieuit die septimo ab uniuerso opere, quod patrauerat" (fol.2-2v) ${ }^{26}$. Con un pasaje del Éxodo, «memento ut diem sabbati sanctifices» ${ }^{27}$, nuestro comentarista destaca la obligación que Dios trasmitió a Moisés de guardar esta fiesta ${ }^{28}$; una fiesta que para los cristianos

23. Debemos precisar que la expresión «Polemoni regi Liciae» aparece también en la traducción de Flavio Josefo AJ 20, cap. 9, de Rufino -Rufinus Aquileiensis (1524: 582)- no obstante, el hecho que el texto latino ofrecido por Patón en otros pasajes donde reproduce a Josefo no corresponda a la traducción de Rufino nos hace creer que no tomó la expresión de este autor.

24. Ivv. 6, 158-160: [...] dedit hunc Agrippa sorori,/obseruant ubi festa mero pede sabbata reges/ et uetus indulget senibus clementia porcis.

25. dona: f. desus. «don, dádiva, regalo» (DRAE).

26. Vvlg. gen. 2.2.

27. Vvlg. exod. 20,8.

28. (fol. $2 \mathrm{v}$ ) «Y después, cuando dio la ley a Moisés en el monte Sinaí en los mandamientos en la primera tabla, en el tercero mandó que se guardase esta fiesta: Memento ut diem Sabbati sanctifices». Patón, como es esperable, computa este mandamiento como el tercero, lo que coincide en el orden con el Decálogo de la Iglesia Católica; Flavio Josefo $A J .3,5,5<91>$, por ejemplo, se refiere al descanso en el cuarto, como corresponde al Decálogo judío: «ó $\delta \dot{\varepsilon} \tau \varepsilon ́ \tau \alpha \rho \tau o \varsigma$

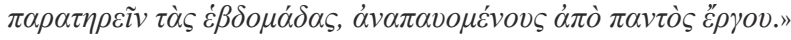


pasó al domingo, del cual «se dice: Haec est dies, quam fecit Dominus, laetemur et exultemus in ea.» (fol. $2 \mathrm{v}$ ). El texto citado por Patón es un pasaje del Libro de los Psalmos, si bien la versión que la Vulgata y la Clementina presentan es: "Haec est dies quam fecit Dominus; exsultemus et laetemur in ea. ${ }^{29}$ " El cambio de orden de los dos verbos se puede deber a la práctica, tan común en la época del humanista, de citar los textos más conocidos de memoria, añadiéndose aquí además el hecho de que las dos formas tienen un significado muy próximo.

Por evidentes cuestiones de espacio no podemos tratar en el presente trabajo toda la información que el autor ofrece del sabbat, pero sí consideramos oportuno reproducir un pasaje que nos permitirá ver una concepción de este que sorprende al lector actual: presentar el sabbat como día de ayuno entre los judíos. Tal concepción, a nuestro entender, está claramente relacionada con las fuentes usadas por Patón. El texto que nos interesa es el que sigue:

Pero el sábado, que en nuestra ley sagrada como figura cesó, entre los judíos fue santísimo y muy de fiesta. Tanto que en él ni aun guisaban de comer, ni salían a ofender al enemigo y en otras muchas cosas mostraban la grande observancia suya, aunque estuviesen entre gentiles, como los mismos lo advirtieron. Y así hacen desta fiesta y de Moisés, su legislador en vez de Dios, muchos dellos muchas veces mención, como se puede ver en Estrabón, Cornelio Tácito, Trogo Pompeyo; Tranquilo en la Vida de Agusto dijo del ayunar de los judíos en sábado: et rursus: 'ne Iudaeus quidem, mi Tiberi, tam diligenter sabbatis ieiunium seruat quam ego hodie seruaui. ${ }^{30} \mathrm{Y}$ por esto les llamaban a los judíos, sabatarios. (fol. 2v)

El maestro de Villanueva explicita que en este día los judíos no cocinaban, «ni aun guisaban de comer», no iniciaban combates, "ni salían a ofender al enemigo", y lo seguían escrupulosamente donde fuera que se encontraran, «aunque estuviesen entre gentiles». Aduce también las referencias al sabbat y a Moisés en el autor griego Estrabón ${ }^{31}$ o en autores romanos como Tácito ${ }^{32}$, Trogo Pompeyo ${ }^{33}$ o Suetonio ${ }^{34}$, este último mencionado como Tranquilo. Todos ellos son citados por Británico s.v. sabbata p. 107:

De Mose autem meminit Strabo, Cornelius Tacitus, Trogus, ergo obseruant festa sabbata, id est celebrant et ieiunio et omnium operum intermissione, quiescunt enim et ieiunant. De ieiunio Tranquillus in Augusto: "Et rursus: 'ne Iudaeus quidem, mi Tiberi, tam diligenter sabbatis ieiunium seruat, quam hodie ego seruaui'». Vnde dicti sunt Sabbatarii. (Britannicus 1551: 107)

\footnotetext{
29. Vvlg. psalm. 117, 24.

30. En el impreso aparece seruari, debe de tratarse de un error de imprenta. $\tau \tilde{\eta} \varsigma v \eta \sigma \tau \varepsilon i \alpha \varsigma \dot{\eta} \mu \dot{\varepsilon} \rho \alpha v$ » se traduce literalmente como «el día del ayuno».

32. Tac. hist. 5, 4.

33. Su obra perdida fue transmitida por Justino: Ivst. 36, 2, 14.

34. Svet. Aug. 76, 2, 4-6.
}

31. Str. 16, 2, 34-39 para Moisés como legislador de los judíos. Str. 16, 2, 40 califica el sabbat como día en que los judíos se abstenían de toda obra, hecho que fue aprovechado por Pompeyo

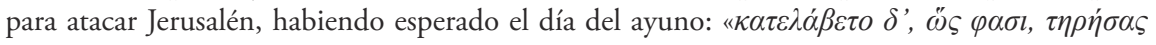

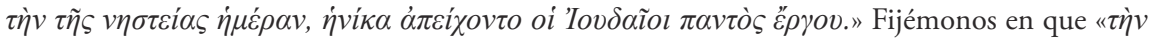


E incluso aparece la denominación de los judíos como sabatarios también referida por Patón.

Respecto al ayuno en el día del sabbat, el maestro solo lo apunta en relación con la cita de Suetonio, pero los autores citados, a excepción de Tácito, sí especifican que se ayunaba. Este dato contradice el conocimiento que se tiene del sabbat en la actualidad, es decir, que en tal celebración el ayuno estaba explícitamente prohibido e incluso podía ser castigado en algunas épocas con la muerte $^{35}$ (Singer 1905: 587-588). Sin embargo, no contradice el conocimiento que tenían los autores griegos y latinos. Diversos estudios prueban que, como mínimo en época clásica, la creencia generalizada fue que el ayuno era un aspecto más del sabbat y así la transmitieron estos autores ${ }^{36}$ (Gruen 2002: 34, Granger Cook 2004: 24-25). Patón, astutamente, no entra en la cuestión y se limita a la expresión "ni [...] guisaban de comer» ${ }^{37}$.

Tomando el sintagma «mero pede», 'con pie descalzo' del verso 159 de la sátira 6, Patón apunta que los judíos celebraban así el sábado, lo que lleva a Tertuliano y a san Jerónimo a llamar a las fiestas del sábado Nudipedalia ${ }^{38}$. A continuación inicia una digresión donde trata de nuevo la figura de Berenice con relación a los pies descalzos, citando un pasaje de Flavio Josefo y parafraseando otro de Hegesipo:

Y Josefo, libro 2, De bello Judaico, dice así hablando de Beronice: Beronice regina, ut Deo uota solueret, pro salute Hierosolyma $[\mathrm{m}]$ uenit, et pro more patrio hostiis caesis, capillisque derasis nudipes ante tribunal stetit. Hegesipo dice lo mismo de la misma, libro 2, De bello Judaico, y añade que le rogó a Festo (otros le llaman Floro), gobernador o presidente de Siria, que hacía gran estrago en su gente, que los perdonase y templase su furia y cólera. Y no le fue de provecho, aunque dice estaba: Nudis pedibus religioni inseruiens.

El texto en griego de Josefo ${ }^{39}$ trata de Berenice pero no coincide literalmente con lo reproducido por Patón; al igual que ocurre con el de Hegesipo que, aunque en latín, tampoco encaja con la cita patoniana. Una vez más notamos

35. Sirva únicamente como ejemplo la entrada Sabbath en Singer.

36. Cf., por ejemplo, Gruen, «A widespread notion had it that the Sabbath was observed as a day of fasting. [...] Writers in the age of Augustus, like Strabo and Pompeius Trogus, simply took for granted the proposition that Jews fasted every Sabbath (Strabo 16.2.40; Trogus apud Justin 36.2.14). Subsequent satirists naturally picked up the idea with pleasure». Granger Cook, "Pompeius Trogus confuses the celebration of the Sabbath with a fast day as did other GrecoRoman authors, but he does not seem to scorn the Sabbath custom as they did».

37. No obstante, debemos precisar que Patón, al tratar la sátira 5 de Persio, afirma: «[Persio] reprehende a los romanos porque también celebraban las fiestas de los judíos, aunque hallo que con diferencia, porque los romanos mezclaban algo de sus ceremonias, que era celebrar las fiestas con buenas comidas, lo que no hacían los judíos» (fol. 3). Afirmación que, debemos confesar, no deja de sorprendernos.

38. Por evidentes cuestiones de espacio y especialmente por el interés filológico y de cuestiones de realia que a nuestros ojos suscita esta forma, dejamos su estudio y el de sus fuentes para otro trabajo.

39. J. BJ 2, 15, 1. 
aquí la dependencia del maestro respecto al comentario de Británico. Así, s.v. mero pede:

Iosephus in secundo libro Belli Iudaici sic scribit: "Berenice regina, ut deo uota solueret pro salute, Hyerosolymam uenit, et pro more patrio hostiis caesis, capillisque derasis, nudipes ante tribunal stetit». (Britannicus 1551: 107)

Se constata que Patón discrepa mínimamente en relación al texto de Josefo. Igualmente el texto de Hegesipo en Británico s.v. mero pede, «nudis pedibus religioni inseruiens» (Britannicus 1551: 107), es idéntico al que ofrece Patón, mientras que las ediciones de Hegesipo transmiten «nudis pedibus adstantem cernerets ${ }^{40}$.

Después de este excurso Patón retoma el tema del sabbat con la exégesis de la expresión de Persio «dies Herodis» del verso 180 de la sátira $5^{41}$. Aunque, según dice, para algunos se trata de la celebración del nacimiento de Herodes, el maestro se decanta por entender que se refiere a la fiesta del sábado:

Y por eso aquí algunos no entienden de la fiesta sábado el común, sino del día del nacimiento de Herodes, que algunos romanos ajudiados celebraban, porque (según escribe Estrabón) Pompeyo en Roma le hizo honra a Herodes de hacello sumo sacerdote de los de su ley y después Agusto (sic) lo hizo rey de Palestina ${ }^{42}$. Pero en decir Sabbata es claro que trata de la fiesta del sábado, si bien mezclada con algunas ceremonias de los romanos. En el cual día acudían de unos y otros a la celebridad, así hombres como mujeres. Por eso Ovidio, libro 1 De arte amandi, aconseja al galán que no solo acuda a las fiestas de los gentiles, antes también vaya a las de los hebreos, que se hacían a cada siete días, porque acudían allá damas ${ }^{43}$. (fol. 3)

Británico, en su comentario a Persio s.v cum Herodis uenere dies, plantea la posibilidad de que «el día de Herodes» haga referencia al sabbat o a otra fiesta

40. Heges. 2, 8, 3-4: "nudis pedibus adstantem cerneret et orantem fastidio haberet.»

41. Pers. 5, 180-184.

42. Str. 16, 2, 46. Ahora bien, según las ediciones modernas del texto de Estrabón, Pompeyo otorgó el título de sumo sacerdote a Hircano; es esta una corrección del helenista Adamantios Coraís y las ediciones anteriores a esta enmienda presentaban el nombre de Herodes. No nos debe extrañar, pues, que Patón reproduzca el texto referido a Herodes. Las fuentes históricas dan la razón a Coraís ya que, según estas, Hircano II fue sumo sacerdote y rey de Judea; después de unos enfrentamientos con su hermano Aristóbulo II, que también se había proclamado rey, y por mediación de Pompeyo, Hircano fue restablecido como sumo sacerdote pero no como rey, pues Judea pasó a ser un protectorado de Roma. Pompeyo tomó Jerusalén en el 63 a.C., Herodes el Grande habría nacido en el 73 a.C. y es evidente que no pudo ser sumo sacerdote con diez años. Así, según el texto griego corregido, Pompeyo concedió el título de sumo sacerdote, $\tau \grave{\eta} v$

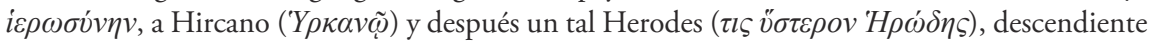

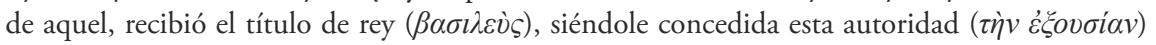

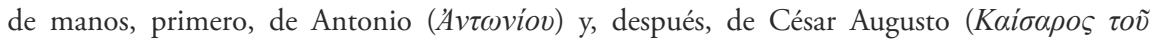
$\left.\sum \varepsilon \beta \alpha \sigma \tau o \tilde{v}\right)$. Britannicus en su comentario de la sátira 5 de Persio, página 603, s.v Herodis puede ser la fuente parafraseada por Patón: «Eius ideo meminit, quia ut scri. Strabo, eum Pompeius sacerdotio Iudaeorum praefecit, [...]. consuetudine praestitit, ut rex fuerit constitutus Antonio primum, postea Caesare Aug. potestatem ei concedente», aunque Patón no menciona a Antonio.

43. A continuación el maestro cita a Ov. Ars 1, 415-416. 
celebrada por los judíos, «i. cum sabbata et alia Iudaeorum festa celebrantur» (Britannicus 1551: 603).

De hecho, entre los comentaristas antiguos consultados, el humanista Juan Bautista Plautio es el único que propone que «dies Herodis» aluda al sabbat y al día del nacimiento de Herodes; así, en su comentario a Persio afirma: "Aut diem natalem Herodis obseruant aut et sabbatum» (Plautius 1520: XCV) ${ }^{44}$.

A pesar de que Patón se posicione a favor del sabbat, la referencia de la expresión "dies Herodis» es una cuestión que todavía sigue abierta. Algunos estudiosos actuales apuntan que se puede tratar del día en que se celebraba el nacimiento de Herodes y su nombramiento como rey de Judea, otros, la Janucá o Fiesta de las Luces o Lucernarias, celebradas en diciembre aún hoy en día, o bien, para otros, la fiesta del sabbat (Rocca 2008: 289-290, Williams 2013: 353-354 $)^{45}$.

La exégesis filológica se repite a propósito del sintagma «tricesima Sabbata» del verso 69 de la sátira 9 del libro 1 de Horacio. Patón afirma que hay unanimidad en las fuentes en llamar al sábado "séptimo día», mientras que la expresión horaciana "quiere decir "sábados treintenes" y no "séptimos" (fol. 4) $y$, por tanto, su interpretación es problemática ${ }^{46}$. Patón presenta el argumento de la sátira, contextualiza la expresión y aporta además las explicaciones de comentadores de Horacio con los que muestra su discrepancia; es el caso de Acrón, actualmente, Pseudo-Acrón ${ }^{47}$ (Badius 1519: fol. 205v), Porfirión (citado como Perfirión) ${ }^{48}$ (Badius 1519: fol. 206), Ascensio ${ }^{49}$ (Badius 1519: fol. 206v), y Juan Villén de Biedma (citado como Bredma) (Villén de Biedma 1599: $196 \mathrm{v})^{50}$; en cambio, concuerda en la explicación del término con el editor y

44. Se trata de una edición conjunta que incluye los comentarios a Persio de Plautio, Británico y Fontio.

45. Ambos trabajos tratan la cuestión y aportan una amplia bibliografía sobre la misma.

46. Las ediciones modernas presentan también divergencias en relación al adjetivo, como lo muestra el aparato crítico de la edición teubneriana que presenta cuatro lecturas diferentes tricensima, tricessima, tricesima y trigesima. De tales divergencias ya se percató el maestro al presentar el texto de Acrón: «El porqué a esta fiesta llámase así, (otros dicen Trigesima y todo es uno) dice Acrón [...]» (fol. 4.)

47. Cita el maestro: "Quae Iudaei Neomenias dicunt, quoniam per Sabbata Iudaei numeros appellant Lunares. Y luego añade: Aliter Trigesima Sabbata dicuntur, quoniam calendis occurrit Sabbatum. Y más: Trigesima Sabbata dicuntur, quoniam ueniunt calendae in prima Luna per Sabbata qui dies a Iudaeis maxime obseruantur. No me satisface» (fol. 4).

48. Leemos en la declaración: «ni lo que dice Perfirión, que es lo mismo: Sabbata Lunaria significat, quia vulgares homines ferias sibi assumunt» (fol. 4). Taraskin (2013) ofrece un estudio de la historia impresa de los escolios de Porfirión y del Pseudo-Acrón y su relación con los comentarios actuales.

49. En la cita patoniana: «Ni lo de Ascensio, que dice: Sabbata Trigesima, quae scilicet Iudaei maxime obseruant sunt sup. hodie» (fol. 4-4v).

50. «Bredma en su declaración magistral dice así: Tricesima Sabbata. Hoy es el día trece del mes y primero de Luna, y sabes que este día es de mucha veneración acerca de los judíos. Llamaban sábados los hebreos a todos los días y solo diferenciaban en llamallos primero o segundo, etc., como iban corriendo, y así contaban primero sábado y segundo sábado y tercero sábado, etc. Y monteándose con Horacio este Fuseo (sic por Fusco) Aristio, su amigo, le dijo que ya lo había 
comentarista horaciano Lambino, al que traduce y cuya explicación completa ${ }^{51}$ (Lambinus 1579: 90). Brevemente, para los tres primeros «tricesima sabbata» denotaría la fiesta de la Neomenia, esto es, la fiesta del primer día del mes que, precisamente, cae en sábado; para Biedma sería un día de Neomenia -puesto que, según él, el sustantivo «sabbata» tendría aquí el significado simplemente de "día»-, para Lambino la expresión haría referencia al sabbat trigésimo del año, que en el calendario judío vendría a coincidir con el Parasceve o Pascua del Cordero. Es esta una cuestión todavía no resuelta por la filología y que supera los objetivos del presente estudio (Singer 1905: 588, Graves 2001: 7) ${ }^{52}$.

\subsection{Otras peculiaridades de la religión y del pueblo judío}

Además de tratar el sabbat, Patón expone y comenta otros rasgos que las fuentes atribuyen al judaísmo y a los que profesan esta religión. Así, los versos 96-99 de la sátira 14 de Juvenal (citada, no obstante, por Patón como 15) sirven al maestro para señalar que Juvenal critica «a los romanos que no guardaban bien su religión gentil, pues también honraban y guardaban esta fiesta» (fol.3) y pasa a tratar diversos rasgos que se atribuyen a los seguidores de la religión judía: adorar únicamente las nubes y a la divinidad celestial, el abstenerse de comer carne de cerdo y la circuncisión.

entendido y, para hacerle regañar, le replicó ser fiesta de los judíos el primero día de la Luna y que no era razón quebrantarlo. Esto dice pero no satisface, ni los demás citados.» (fol. 4v). Patón cita literalmente el texto de Biedma pero tras «así contaban primero sábado y segundo sábado y tercero sábado, etc.» omite "como nosotros decimos Domingo, Lunes, Martes, etc.».

51. Refiere el comentarista: «Empero quien nos da luz para venir a lo cierto es Lambino que, mal contento destas declaraciones y de la propria suya, dice que lo consultó con un docto hebreo y le dijo cosas que vino a colegir que por Tricesima Sabbata se entiende la fiesta más principal de las suyas, como lo era la Pascua del Parasceve, que celebraban con lechugas amargas y la cena del cordero, por esto llamado Pascual (y por nuestros teólogos típico y figurativo). La razón es que, como la Iglesia latina cuenta sus Dominicas teniendo cuenta con alguna fiesta o tiempo principal, diciendo Dominica quarta, quinta, etc. post Pentecostem, o Septuagesima o Sexagesima, Quinquagesima respeto de la de Pasión, estos, teniendo atención al principio de su año, que era en la luna de setiembre, iban contando fiestas y sábados posteriores o subsecuentes y, respeto deste principio, la fiesta de Parasceve era a los 29 sábados o 30 en la menguante de marzo, y así quiso decir la tal fiesta y no la fiesta llamada Neomenia; aunque dicen que esta se celebraba a los treinta de cada mes, y no es así, sino el primer día del mes, porque estos entre ellos se comenzaban el primer día de Luna, que lo era del mes. Y decir esto es volvernos a las primeras interpretaciones. Y así por lo más cierto tengo que era el Parasceve o Pascua de cordero por la razón dicha.» (fol. 4v).

52. Así, por ejemplo, en la entrada Sabbath en Singer : «Horace, in his "Satires" (i. 9, 69), speaks of "tricesima Sabbata", which certainly does not refer to a Sabbath so numbered by the Jews». Graves, después de estudiar algunos de los autores mencionados y otros posteriores, defiende, y nosotros estaríamos próximos a su opinión, que «It would seem, therefore, that the problem of tricesima sabbata is best solved by referring it to an obvious Jewish festival (the New Moon), taking the phrase grammatically as one unit (not as a New Moon which is also a Sabbath), and by allowing for some license on Horace's part in constructing the dialogue for his friend Aristius (who uses his knowledge of the Jews for the sake of the joke, but who does not know too much about Jews). If this is correct, tricesima sabbata means "the festival of the thirtieth day", a festival erroneously referred to as "Sabbath"». 
Patón se opone a que los judíos adoren las nubes pero acepta que no coman carne porcina «tanto se guardan de comer carne de puerco como si fuera carne humana y así los tales animales se morían de viejos, como no los mataban para comer» (fol. 3-3v) y que practiquen la circuncisión (Howell Chapman 2006) ${ }^{53}$, y lo refuerza con referencias al segundo libro de los Macabeos $^{54}$, Estrabón ${ }^{55}$, Tácito $^{56}$, Persio ${ }^{57}$ y Marcial $^{58}$. Exceptuando la referencia bíblica, todos ellos aparecen en el comentario de Británico de la sátira 14, s.v. praeputia ponunt (Britannicus 1551: 269) y s.v. verpos (Britannicus 1551: 269).

A continuación Patón comenta los versos 100-109 de la misma sátira de Juvenal (referenciada de nuevo como 15). En ellos el poeta destaca en el comportamiento judío la dependencia de las Leyes Sagradas y de «su legislador Moisés " ${ }^{59}$; critica en los romanos convertidos al judaísmo el desprecio por las leyes y las ceremonias romanas, y censura el seguimiento que padres e hijos, instruidos estos por sus progenitores, hacen de las leyes y ceremonias judías. Es, no obstante, apunta el maestro, en la práctica de la avaricia donde los jóvenes romanos se sienten más forzados y más distantes del carácter judío:

En lo que fuerzan su natural es que como mozos quisieran gastar más liberalmente, mas los padres con sus consejos los obligan a ser avarientos (vicio antiguo en esta nación y hoy no dejado) y se lo aconsejan con aparencia y nombre de virtud, que no hay como más engañe la pestilencia de la culpa y pecado. (fol. 3v-4).

\section{CONCLUSIÓN}

De todo lo que acabamos de exponer es conveniente recuperar algunos aspectos filológicos que se relacionan, primero, con las fuentes y el contenido de la declaración magistral estudiada, y segundo, con la manifestación del pensamiento patoniano en ella.

53. Para la circuncisión judía, las referencias bílicas y Josefo, cf. Howell Chapman.

54. Vvlg. II Macc., 7, 1-41.

55. Stra. 16, 2, 37.

56. Tac. hist. 5, 4, 2 y 5, 5, 2.

57. Verso 184 de Pers. 5, citado en (fol. 2v).

58. «Marcial libro 7, epis [epigrama] 24» (fol. 3v), en las ediciones modernas Mart. 7, 30, 5, y «Marcial llamó al circunciso uerpus, ultrajando de judío a Menófilo, libro 7, epis [epigrama] 81," (fol. 3v), en las ediciones modernas Mart. 7, 82, 6.

59. «Diciendo la grande observancia que ponían en su ley los judíos, Juvenal dice que por guardalla con toda religión y reverencia no hacían caso de las leyes y ceremonias romanas, sino temían, guardaban, respetaban y reverenciaban, como cosa sagrada y santa, sus leyes y derecho judaico, y todo lo que les había dejado en él su legislador Moisés en los libros y tablas de la ley» (fol. 3v). De nuevo es inevitable ver en las palabras de Patón el comentario de Britannicus, página 269, s.v. arcano u. [uolumine]: "Pentateuchum intelligit. i. quinque uolumina ueteris foederis a Mose conscripta, uidelicet, Genesim, Exodum, Leuiticum, Numeros, Deuter. dictum autem Pentateuchum [...], in quo Deus leges dedit Mosi, quae seruabantur in arcanis, eas Moses tradidit Iudaeis." 
En lo que respecta al primer aspecto, es conveniente apuntar la imprecisión con que Patón, siguiendo la costumbre de la época y del propio autor, referencia los textos antiguos. Así, por ejemplo, cuando comenta las sátiras, no menciona en ningún caso los números de verso ni cuando los cita en bloque ni cuando trata un único verso ${ }^{60}$; al ofrecer las referencias de otros autores, exceptuando Josefo, Suetonio y Ovidio, estas no contienen el título de la obra, ni siquiera en el caso de autores cuya producción es ciertamente vasta. Es innegable, por otro lado, que el maestro comete errores o imprecisiones; ahora bien, según nuestra investigación, en la mayoría de los casos suelen ser atribuibles a las fuentes de las que tan dependiente se muestra -es el caso, por ejemplo, de la confusión en torno a la figura de Polemón, rey de Cilicia y no de Licia-, a errores de impresión -la referencia a Bredma en lugar de Biedma por citar solo uno-, aunque en lo que respecta a otros, creemos que son imputables a nuestro autor-así, el hecho de citar la sátira 14 de Horacio como 15, pues esta aparece ya como 14 en el comentario de Británico y en otros textos de la época, cuyo conocimiento y uso por Patón ya ha sido probado por Maria del Carme Bosch en diversos trabajos (Bosch 2009 y 2012) ${ }^{61}$.

Tomando las palabras de Bosch (2009: 241), en sus obras Patón «hace gala sobre todo de una cultura libresca, pero esta, lejos de empequeñecerle, ofrece una magnífica prueba de la enseñanza de la época». En la presente declaración, no obstante, la dependencia patoniana del comentario de Británico es absoluta. Las divergencias respecto de los textos griegos y latinos y su presentación a través del filtro del comentario de Británico nos lleva a afirmar que Patón usa sus fuentes de manera indirecta, a partir de una segunda mano. Es más, el texto del comentario le sirve como fuente de citas e, incluso, de inspiración para exponer el contenido. En el momento final de la redacción de este trabajo, Bosch nos ha confirmado definitivamente el uso del comentario de Británico por parte del maestro, pues en el manuscrito del «Libro decimo octavo» de los Comentarios de erudición ${ }^{62}$, Patón aporta dos citas textuales de Británico, la primera en el comentario a «uno asse» de la sátira 10, verso 116 de Juvenal (f. 210v), y la segunda en «Adulter publicus» de la misma sátira, versos 311-312 (f. 235).

No obstante, y situados aún en el campo filológico, debemos hacer notar la valentía de Patón al tratar y posicionarse en cuestiones que todavía siguen abiertas -la exégesis de «dies Herodis» o de "tricesima sabbata»-. El mero hecho de despertar su interés ya prueba la agudeza de nuestro estudioso.

60. Sirva para ilustrarlo el hecho de que no explicita el número de los versos de la sátira 6 con los que inicia su declaración, tampoco precisa el verso 180 de la sátira 5 de Persio que contiene la expresión «dies Herodis», ni el verso 69 de la sátira 9, libro 1 de Horacio con la forma «tricesima sabbata» de las que, sin embargo, se ocupa prolijamente.

61. Bosch demuestra que el autor conocía y usaba la Polyanthea. Así, en Nanus Mirabellius y Amantius (1574), esta sátira aparece referenciada ya como sátira 14; sirva de ejemplo la página 104 donde s.v. auaritia los versos 107-112 son atribuidos a la sátira 14.

62. De su edición crítica, actualmente en prensa, se ocupan M. del Carme Bosch, Jaume Garau, Abraham Madroñal y Juan Miguel Monterrubio. 
Ya pasando al segundo aspecto, la declaración muestra en diversos puntos la huella del pensamiento patoniano. Como hemos visto, el ataque desmesurado o incluso furibundo a las mujeres es uno de los principales temas del texto. Desde nuestra mirada las palabras de Patón merecerían el calificativo de misóginas, como ya las merecieron las de Juvenal en la sátira comentada. Ahora bien, no es nuestro objetivo ni nuestro interés tratar este aspecto, sino simplemente ponerlo en relación con el paralelismo que Patón, de la mano de su amigo Quevedo, establecía entre el comportamiento de las mujeres y la riqueza de sus hogares con el proceder de la sociedad y la época de crisis que les tocó vivir. Como bien ya señala Madroñal (2011), la decadencia de la sociedad del siglo XVII es atribuida por Patón tanto a la ociosidad y holgazanería de los españoles como al deseo de aparentar, que implica unos gastos excesivos y, por tanto, la ruina de las haciendas. Sin embargo, según nuestro humanista, tal deseo de aparentar y, en consecuencia, de gastar en demasía, no es exclusivo de la mujer sino que también afecta al hombre; no en vano, en la Reforma de trajes habla de «los escesos en gastar en trajes así hombres como mujeres» ${ }^{63}$. En la declaración que nos ocupa, no obstante, el objeto de crítica en este sentido es, como ya hemos visto, de manera exclusiva la mujer ${ }^{64}$.

Por otra parte, a lo largo de nuestra exposición se evidencia un cierto antisemitismo en el texto patoniano, tan tradicional en el autor y en la época. En cambio, en la declaración no destaca el recurso, estudiado por Jaume Garau y tan frecuente en Patón, de cristianizar a los clásicos persiguiendo un afán moralizador (Garau 2014a y 2014b).

No podemos concluir este estudio sin mencionar la facilidad con que Patón corta la línea discursiva del texto y las constantes digresiones -filológicas o de realia- que interrumpen la evolución temática de la declaración. Sirva como ilustración de ello el mero hecho de que el asunto de partida, la crítica del defecto femenino de ambicionar alhajas y otros objetos lujosos, tan adecuado para un comentario de la sátira 6 de Juvenal, inicia y concluye el texto en una composición circular que, a nuestro entender, pretende darle unidad temática, pero que se convierte en realidad en un mero pretexto para tratar otra cuestión que parece interesar más al autor, el sabbat y otros aspectos relacionados con los

63. Reforma de trajes, p. 131, citamos por la edición de la obra realizada por Madroñal (2011). Afirma además Madroñal, página 46: «Para el moralista que era Patón, una de las principales causas de esta decadencia era la ociosidad y la holgazanería de los españoles, también el deseo de aparentar, de ahí el excesivo gasto en los trajes y la ruina que acarrea en las economías: "Pues no hay mayor desigualdad que querer que todo sea igual. Dos cosas tienen perdida España: la principal es la ociosidad, la otra (y procede desta) los escesos en gastar en trajes así hombres como mujeres. La ambiciosa pobreza engendra la temeraria competencia, esta la holgazanería y esta el esceso de gastos" — Reforma de trajes, 1638, f. 26.» También asevera Madroñal, página 31, en relación al Discurso de los tufos: «Patón no se cansa de censurar la manía, especialmente de las mujeres, de gastar los dineros del marido en costosos trajes».

64. En cambio, y aunque Patón no lo comente, en la sátira 6 de Juvenal el hombre también recibe su porción de crítica, si bien el motivo es otro: en el hipotético caso de que los hombres amen a sus mujeres, lo que en realidad aman es su dote o una belleza mientras duren (vv. 136147). 
judíos ${ }^{65}$. Incluso sorprende al lector la brusquedad con que, después de haber dejado en el folio 2 el tema de la ambición de las mujeres y no haberlo tratado durante el resto de la declaración, lo retoma al final del folio 4v. Lo ilustramos, ya para terminar, con las palabras del maestro que precisamente cierran la declaración:

[a propósito de tricesima sabbata] Y así por lo más cierto, tengo que era el Parasceve o Pascua de cordero por la razón dicha.

Con que queda declarado lo que a esta parte de la sátira de Juvenal toca, convidando a los curiosos a la leción que, ocasionado desta, quiero declarar continuando la fiesta deste sábado fin de la ley legal y principio de la de gracia, en que llegó el del perfeto descanso.

Aquí debemos notar el exceso del gasto de las mujeres ambiciosas en galas, poderoso a empobrecer el caudal de los maridos, aunque sean ricos, siendo ellas ambiciosas desto, y de las que dijo Terencio:

Satrapes si sit amator, sumptus eius ferre nequeat. (fol. 4v)

Si su amante fuera un sátrapa, sería incapaz de soportar sus gastos ${ }^{66}$.

\section{Bibliografía}

Badius J., Opera Q. Horatii Flacci Poetae amoenissimi cum quattor commentariis Acronis, Porphyrionis, Anto. Mancinelli, Jodoci Badii Ascensii accurate repositis, cumque adnotationibus Matthaei Bonfini et Aldi Manutii Romani a Philologo recognitis: suisque locis insertis et ad finem ex integro restitutis. Praemisso amplissimo in uniuersum opus indice. Parisiis, uia Iacobea, 1519.

Beardsley Th. S., «Bartolomé Jiménez Patón y Marcial: el problema bibliográfico», en VV. AA., Homenaje a Antonio Pérez Gómez, t. I. Cieza, La Fonte que Mana y Corre, 1978, pp. 91-101.

- «Bartolomé Jiménez Patón: The "Lost" and Unknown Works», en Damiani B. M. (ed.), Renaissance and Golden Age Essays In Honor of D. W. McPheeters. Potomac, Scripta Humanistica, 1986, pp. 1-25.

Beltrán Ma. T., Sánchez-Lafuente A., «La Sátira Sexta de Juvenal o el tópico de la misoginia", Myrtia, 2008, 23, pp. 225-243.

Bosch M. del C., "El libro III de las Odas de Horacio, comentado y traducido por Bartolomé Jiménez Patón», Anuari de Filologia, Studia Graeca et Latina, 20012002, Vol. XXIII-XXIV, 11, pp. 33-42.

- «Los autores griegos en el libro decimosexto de los Comentarios de erudición de Bartolomé Jiménez Patón», Faventia, 2009, 31/1-2, pp. 227-241.

65. Aunque sea puramente anecdótico, la falta de unidad temática, los cambios de tema injustificados y las digresiones excesivas son también propios de Juvenal. No en vano el autor se formó en la edad de la retórica y en ella el artificio, el virtuosismo oratorio y los efectos chocantes contaban más que un conjunto esmeradamente construido.

66. Ter. Haut. 452-453. La traducción es nuestra. 
- «Gentiles y cristianos en El virtuoso discreto de Bartolomé Jiménez Patón», Studia philologica Valentina, 2012, vol. 14, n. s. 11, pp. 179-201.

Britannicus I., Iunii Iuvenalis et A. Persii Flacci, satyrae cum doctissimorum virorum commentariis atque annotationibus: omnium quorum in hunc diem aliquid editum extat, quorum nomina versa pagina declarabit:his accessere Caelii Secundi Curionis nova scholia, quibus tum praeterita ab aliis explicantur, tum male intellecta corriguntur:quinetiam Graeca quibus Britannicus in Iuvenalis commentariis usus est, Latinorumque autorum loci, quae omnia miris modis corrupta fuerant, restituuntur: additus est index copiosissimus, et utilissimus. Basileae, Froben, 1551.

Cózar Castańar J., "Himno latino a santa María Magdalena», Boletín del Instituto de Estudios Giennenses, 2007, 195, pp. 9-49.

Garau J., «Ideas religiosas del Maestro Bartolomé Jiménez Patón (1569-1640) en El virtuoso discreto [c.1629-1631]", Hispania Sacra, 2012, LXIV, 129, pp. 237-258.

- «El humanismo de Bartolomé Jiménez Patón a la luz de nuevos textos», Rilce, 2014a, 30.2, pp. 31-54.

- «La autoridad de los clásicos en la obra no filológica de Bartolomé Jiménez Patón», en Strosetzki Chr. (ed.), La Autoridad en la Antigüedad, Madrid, Frankfurt am Main, Universidad de Navarra, Iberoamericana, Vervuert, 2014b, pp. 99-127.

Gelenius S., Flauii Iosephi Antiquitatum Iudaicarum libri XX: adiecta in fine appendicis loco Vita Iosephi per ipsum conscripta / à Sigismundo Gelenio conuersi; De bello Iudaico libri VII, ex collatione Graecorum codicum per Sig. Gelenium castigati; Contra Apionem libri II, pro corruptissimis antea, iam ex Graeco itidem non solùm emendati, sed etiam suppleti opera eiusdem Gelenii; De imperio rationis, siue De Machabaeis liber unus à Des. Erasmo Roterodamo recognitus. Basileae, Froben, 1554.

- Flauii Josephi Hierosolymitani Sacerdotis Opera quae extant omnia, nempe Antiquitatum Judaicarum libri XX, Sigismundo Gelenio interprete, De bello Judaico libri VII, interprete Rufino Aquileiensi, Liber de vita sua cum interpretatione Gelenii, Adversus Apionem libri II cum uersione antiqua à Gelenio emendata, et De Maccabaeis seu de Imperio rationis liber cum paraphrasi Erasmi Roterodami. Coloniae, Sumptibus Mauritii Georgii Weidmanni, 1691, p. 693.

Gil J., "Marcial en Espańa», Humanitas, 2004, 56, pp. 225-327.

Granger Cook J., The Interpretation of the Old Testament in Greco-Roman Paganism. Tübingen, Mohr Siebeck, 2004.

Graves M., "Tricesima sabbata: Horace’s “Thirtieth Sabbath” (Satires I, 9) and Jewish Festival Days», Ohio, 2001 [consultado el 2 noviembre 2014]. Disponible en: http://www.wheaton.edu/Academics/Faculty/G/Michael-Graves

Gruen E. S., "Roman perspectives on the Jews in the age of the Great Revolt» en Berlin A. M. y Overman J. A. (eds.), The First Jewish Revolt Archaeology, history, and ideology, London-New York, Routledge, 2002, pp. 27-42.

Hodgart M., La sátira, Madrid, Guadarrama, 1969.

Howell Chapman H., "Paul, Josephus, and the Judean Nationalistic and Imperialistic Policy of Forced Circumcision», Ilu. Revista de Ciencias de las Religiones, 2006, 11, pp. 131-155.

Jiménez Patón B., Elocuencia española en arte. Toledo, T. de Guzmán, 1604. Obra incluida en Mercurius Trimegistus. Baeza, Pedro de la Cuesta Gallo, 1621. 
- Declaración magistral destos versos de Juvenal. Sátira 6. Cuenca, Salvador de Viader. Impreso contenido en el volumen Colección de temas gramaticales, Biblioteca Nacional de España, 1632, pp. 59-62v.

- Reforma de trajes. Doctrina de fray Hernando de Talavera, primer arzobispo de Granada. Baeza, J. de la Cuesta, 1638. Edición en Madroñal (2011).

- Discurso de los tufos, copetes y calvas. Baeza, J. de la Cuesta, 1639. Edición en Madroñal (2011).

- Comentarios de erudición ("Libro decimosexto»), edición crítica, introducción y notas de M. del C. Bosch, J. Garau Amengual, A. Madroñal Durán y J. M. Monterrubio Prieto, Madrid/ Frankfurt, Iberoamericana, Vervuert, CSIC, 2010.

- El virtuoso discreto. Primera y segunda parte, edición crítica, introducción y notas de J. Garau y M. del C. Bosch. Madrid, Frankfurt am Main, Iberoamericana, Vervuert, 2014.

Lambinus D., Q. Horatii Flacci sermonum, seu satyrarum, seu eclogarum libri duo: epistolarum libri totidem. A Dionysio Lambino Monstroliensi ex fide et authoritate complurium librorum manuscriptorum emendati, et commentariis copiosissimis explicati, pars altera. Lutetiae, apud Ioannem Macaeum, 1579.

Madroñal A., "Aportaciones al estudio del maestro Jiménez Patón (dos obras inéditas y casi desconocidas)», Criticón, 1993, 59, pp. 83-97.

- Humanismo y Filología en el Siglo de Oro. En torno a la obra inédita de Bartolomé Jiménez Patón. Madrid, Universidad de Navarra, Iberoamericana, Vervuert, 2009.

- Sociedad, pobreza y moda en la España del Siglo de Oro (Según la obra última de Bartolomé Jiménez Patón). Saarbrücken, Editorial Académica Española, 2011.

Menéndez Pelayo M., Bibliografía Hispano-Latina Clásica, vol. 6. Santander, CSIC, 1953.

Nanus Mirabellius, D., Amantius B., Polyanthea: hoc est, opus suauissimis floribus celebriorum sententiarum tam Graecarum quam Latinarum, exornatum..., Coloniae, Maternum Cholinum, 1574.

Plautius I. B., Auli Flacci Persii satyrographi clarissimi Opus emendatum. Interpretantibus Ioanne Baptista Plautio Cornutoque philosopho eius praeceptore necnon Ioanne Britannico Brixiano ac Bartholomeo Fontio uiris eruditissimis cum suis figuris et utilissimis apostillis. Insuper alphabetica tabula nuper apposita, quae omnia scitu digna mirifice complectitur. Venetiis, in casis Bernardini de Vianis de Lexona Vercellensis, 1520.

Rocca S., Herod's Judaea. Tübingen, Mohr Siebeck, 2008.

Rufinus Aquileiensis, Flauii Iosephi, patria Hierosolymitani, religione Iudaei, inter Graecos historiographos, cum primis facundis, opera quaedam Ruffino presbytero interprete, in quibus post ultimam aliorum aeditionem, loca nec pauca, nec omnino leuis momenti ex uetustissimorum codicum collatione restituta comperies lector. Basileae, apud Io. Frobenium, 1524.

Singer I. (ed.), The Jewish encyclopedia, vol. 10. New York-London, Funk and Wagnalls Company, 1905. 
Taraskin P., «Horace scholiasts Porphyrio and 'Acro' in early modern printed editions (1474-1838)», Studia Aurea, 2013, 7, pp. 339-364.

Villén de Biedma J., Q. Horacio Flacco poeta lyrico latino. Sus obras con la declaracion Magistral en lengua Castellana. Por el Doctor Villen de Biedma. Granada, Sebastián de Mena, 1599.

Williams M. H., Jews in a Graeco-Roman Environment. Tübingen, Mohr Siebeck, 2013. 
